\title{
CORRIGENDUM \\ The Tunguska event and Cheko lake origin: dendrochronological analysis-Corrigendum
}

\author{
Rosanna Fantucci, Romano Serra, Gunther Kletetschka and Mario Di Martino
}

doi.org/10.1017/S1473550414000445, published by Cambridge University Press, 23 October 2014.

In the above-mentioned paper (Fantucci et al 2014), the author regrets to announce that the author names were published incorrectly. The correct order is supplied below.

\section{Reference}

Fantucci, R., Serra, R., Kletetschka, G. \& Di Martino, M. (2014). The Tunguska event and Cheko lake origin: dendrochronological analysis. The Journal of Astrobiology, published online July 2015, doi: 10.1017/S1473550414000445. 